\title{
Vascular Remodelling and Mesenchymal Transition in Systemic Sclerosis
}

\author{
Pier Andrea Nicolosi, ${ }^{1}$ Enrico Tombetti, ${ }^{2}$ Norma Maugeri, ${ }^{2}$ Patrizia Rovere-Querini, \\ Silvia Brunelli, ${ }^{1}$ and Angelo A. Manfredi ${ }^{2}$ \\ ${ }^{1}$ School of Medicine and Surgery, University of Milano-Bicocca, 20900 Monza, Italy \\ ${ }^{2}$ Unit of Medicine and Division of Immunology, Transplantation and Infectious Diseases, \\ San Raffaele Scientific Institute and Vita-Salute San Raffaele University, 20132 Milano, Italy \\ Correspondence should be addressed to Angelo A. Manfredi; manfredi.angelo@hsr.it
}

Received 4 December 2015; Revised 9 February 2016; Accepted 10 February 2016

Academic Editor: Heinrich Sauer

Copyright (c) 2016 Pier Andrea Nicolosi et al. This is an open access article distributed under the Creative Commons Attribution License, which permits unrestricted use, distribution, and reproduction in any medium, provided the original work is properly cited.

\begin{abstract}
Fibrosis of the skin and of internal organs, autoimmunity, and vascular inflammation are hallmarks of Systemic Sclerosis (SSc). The injury and activation of endothelial cells, with hyperplasia of the intima and eventual obliteration of the vascular lumen, are early features of SSc. Reduced capillary blood flow coupled with deficient angiogenesis leads to chronic hypoxia and tissue ischemia, enforcing a positive feed-forward loop sustaining vascular remodelling, further exacerbated by extracellular matrix accumulation due to fibrosis. Despite numerous developments and a growing number of controlled clinical trials no treatment has been shown so far to alter SSc natural history, outlining the need of further investigation in the molecular pathways involved in the pathogenesis of the disease. We review some processes potentially involved in SSc vasculopathy, with attention to the possible effect of sustained vascular inflammation on the plasticity of vascular cells. Specifically we focus on mesenchymal transition, a key phenomenon in the cardiac and vascular development as well as in the remodelling of injured vessels. Recent work supports the role of transforming growth factor-beta, Wnt, and Notch signaling in these processes. Importantly, endothelial-mesenchymal transition may be reversible, possibly offering novel cues for treatment.
\end{abstract}

\section{The Scenario: Damage and Remodelling of the Microvasculature in Systemic Sclerosis}

Systemic Sclerosis (SSc) is a multisystem disease, characterized by autoimmunity, a broad microvasculopathy, and fibrosis of the skin and of visceral organs. Events still poorly characterized support the activation of myofibroblasts and self-amplifying circles lead to aberrant and sustained fibrogenesis [1]. Injury and activation of endothelial cell linings are early events in the natural history of SSc [2, 3] and excessive/deregulated innate immune responses in response to vessel and tissue injuries are hallmarks of SSc [4-8]. Vascular inflammation and remodelling characterize diverse districts, including the lung, the heart, the skin, and the kidney. Small- and medium-size arteries are usually involved, with the frequent intimal hyperplasia, medial thickening, obliteration of the lumen, perivascular inflammation, and occasionally microthrombi $[9,10]$ (see also below). SSc also affects capillaries. Nailfold capillaroscopy, which is routinely used in the clinical settings, often reveals dilatation of capillaries in early stages and loss in later phases, an event that possibly represents the counterpart of the lumen obliteration of small arteries in other tissues [11], a process that involves the proliferation of the intimal layer, with accumulation of constituents of the extracellular matrix $[3,12]$.

Of importance, the occlusion of the microvasculature results in persistent hypoxia of peripheral tissues, which in turn is not repaired by the physiologic mechanisms of vasculogenesis or angiogenesis [13]. Hypoxia represents a massive stimulus for the generation of various growth factors that influence the fate of vascular cells, prompting mesenchymal transition and fibrosis $[14,15]$. On the other hand hypoxia is a key element prompting oxidative stress, another hallmark of SSc [12]. 


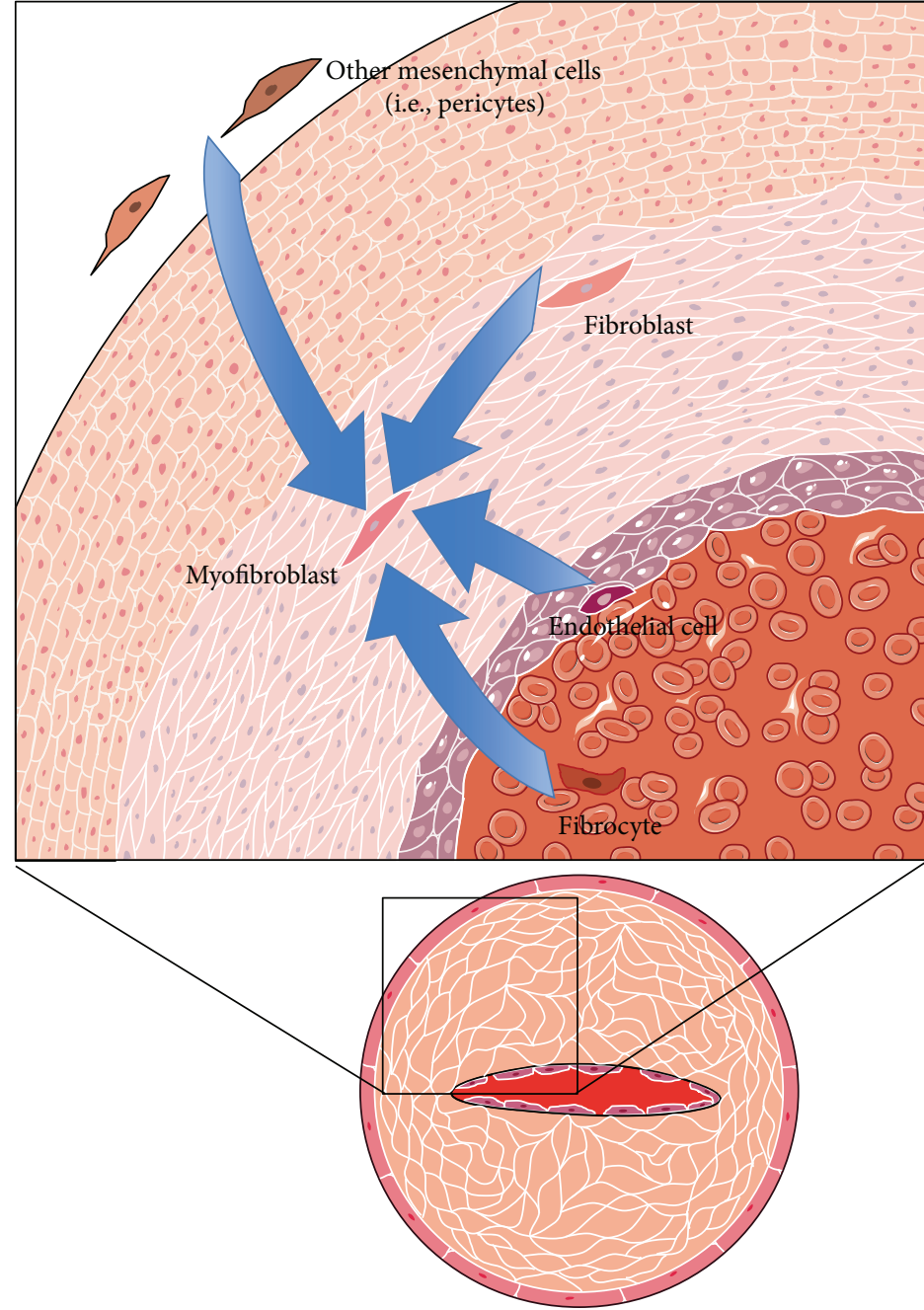

(a)

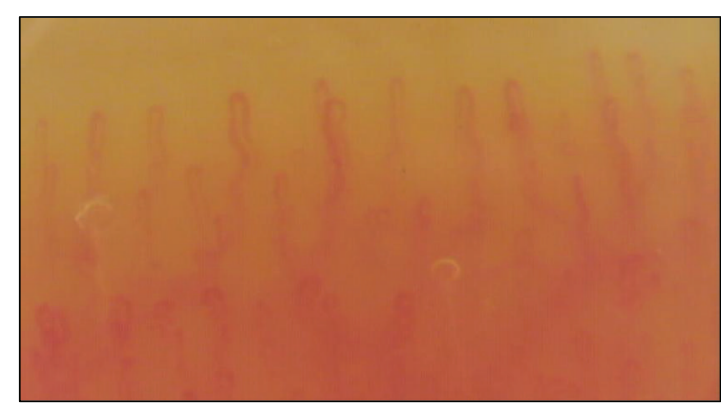

(b)

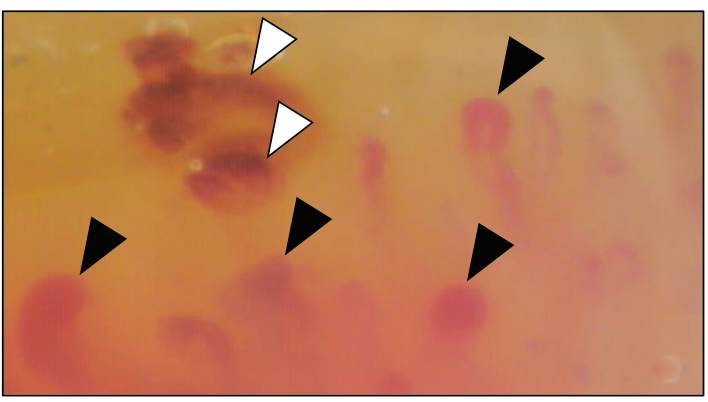

(c)

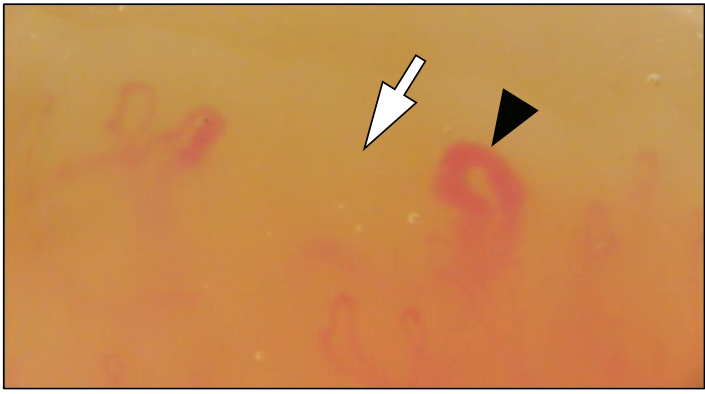

(d)

FIGURE 1: Vascular remodelling and capillaroscopic pattern in Systemic Sclerosis (SSc). (a) Stenoocclusive remodelling in SSc microvasculature (bottom right) is believed to result from an abnormal reparative attempt triggered by chronic endothelial damage, which drives intima-media hyperplasia and increased ECM production within the vessel wall. Mesenchymal cells, specifically myofibroblasts with a highly secretory phenotype, are the main final effectors responsible for these structural changes. Myofibroblasts in SSc vessels can originate from multiple cellular sources (upper left), either of mesenchymal origin, such as pericytes or fibroblast, or of nonmesenchymal origin, such as endothelial cells. (b)-(d) Capillaroscopic pattern in normal subjects (b) and scleroderma patients at magnification 200x ((c): "active" SSc pattern; (d): "late" SSc pattern). Note the heterogeneity in the architecture and morphology of SSc capillaries with frequent ectasias (black arrowheads). In the "active" scleroderma pattern there are plenty of giant capillaries (i.e., more than $50 \mu \mathrm{m}$ of diameter) and microhaemorrhages (white arrowheads), with mild loss of capillaries. In the "late" scleroderma pattern giant capillaries and microhaemorrhages are less frequent, but a severe loss of capillaries is evident, with extensive avascular areas (white arrows).

Soluble moieties present in the blood of SSc patients activate and induce in the presence of neutrophils the programmed death via apoptosis of endothelial cells [16], suggesting that inflammatory leukocytes directly contribute to the endothelial injury [17]. The apoptosis of endothelial cells [3], the aberrant expression of transcription factors [1820], of cytokines and of growth factors, specifically including the production of the antiangiogenic VEGF165b isoform of the vascular endothelial growth factor (VEGF) [21], alterations of pathways activated by the interaction of components of the class III semaphorin family and of their receptors, Plexin-D1 and Neuropilin-1 [22, 23], and the defects of sprouting angiogenesis and vasculogenesis participate in the remodelling of the vasculature [24]. The events occurring at the cellular levels are poorly characterized. The recent insight on the relative plasticity of vascular cells, including ECs and pericytes, raises the possibility that transdifferentiation programs are activated and contribute to the maladaptive remodelling characteristic of the SSc vasculature (Figure 1).

Platelets are critical players in vascular remodelling. As guardians of the integrity of the vessels platelets respond to the early changes of the endothelial lining undergoing a burst of activation, which become persistent and sustained activation [25-27]. They represent a source of VEGF, which acts 
on endothelial cells [28]. Moreover they generate and release an array of profibrotic signals, including transforming growth factor- $\beta$ (TGF- $\beta$ ), platelet-derived growth factor (PDGF), and serotonin [15]. Thrombosis of microvessels is frequent in SSc and could be facilitated by the release from damaged and activated endothelial cells of extralarge multimers of von Willebrand Factor (vWF) [29]. Platelets also contain a substantial amount of the High Mobility Group Box1 (HMGB1) protein [30], a prototypic Damage Associated Molecular Pattern (DAMP) [31].

HMGB1 is a key signal shaping the characteristics of the inflammatory response elicited in response to sterile and microbial insults $[32,33]$. It mediates the homeostatic response to injury [34-37], prompting fibrogenesis in response to endothelial damage [38-41] and playing a nonredundant role in the remodelling of vessels that takes place in injured tissues $[42,43]$. Blood levels of HMGB1 are elevated in patients with SSc [44]. Conversely platelets of SSc patients undergo the depletion of the intracellular HMGB1 content [45]. The two events possibly reflect the generation of $\mathrm{HMGB1}^{+}$microparticles ( $\left.\mu \mathrm{Ps}\right)$, an event that seems to dominate the release of the molecule from activated platelets $[46,47]$.

Platelets are an established source of $\mu \mathrm{Ps}$ and plateletderived $\mu$ Ps in the plasma of patients with SSc are abundant $[48,49] . \mu$ Ps have various actions that might be involved in the natural history of the disease, including the regulation of the survival and of the activation state of endothelial cells and, importantly, of endothelial cell precursors [50, 51]. Moreover, subpopulations of $\mu$ Ps might be associated with specific features of SSc, including lung involvement and the extent of fibrosis [52]. $\mathrm{HMGB1}^{+} \mu \mathrm{Ps}$ purified from SSc patients, but not $\mathrm{HMGBl}^{-} \mu$ Ps purified from control subjects, activate human leukocytes while HMGB1 inhibitors reverse the effects in vitro, suggesting that the moiety might be important in the maintenance of the SSc vascular inflammation [46].

Of importance, HMGB1 is a redox-sensitive moiety [53]. HMGB1 contains cysteine residues in positions 23,45 , and 106 and resides in a predominantly reduced state in the nucleus and the cytosol [53-55]. Reduced HMGB1 in the extracellular environment forms bioactive complexes with the CXCL12/SDF1 chemokine and effectively triggers in vitro cell migration [53, 56-59]. An oxidizing environment in contrast enhances the ability of the molecule to prompt the secretion of inflammatory cytokines from macrophages and to promote autoimmunity [59-65]. Oxidative stress is a critical player in SSc, which contributes to the persistent activation of fibroblasts and of vascular cells $[12,66]$. Indeed oxidation is critical for HMGB1 ability to support the activation of blood leukocytes in response to plateletsor $\mu$ Ps-derived signals [46] and possibly for their action on vascular cells, including pericytes $[67,68]$. Platelet-derived HMGB1 is gaining increasing attention as a key moiety in intravascular immunity and in the activation/regulation of the coagulation cascade $[45-47,69,70]$. Further studies are necessary to validate the involvement of this pathway in SSc and specifically to reveal whether it might contribute to the remodelling of the microcirculation in particular. Of interest, HMGB1 has a well-characterized fibrogenic action and is an established inducer of epithelial-to-mesenchymal transition (EMT), a process that is associated with the origin of myofibroblasts from various precursors, including those associated with the vessel wall [40] (see below).

Other nonmural cells, such as fibrocytes and macrophages, might play a role in the development of the fibroproliferative vasculopathy in SSc. Circulating fibrocytes comprise bone marrow-derived cells that have both hematopoietic and mesenchymal features, endowed with a physiologic role in the physiologic wound healing [71]. Fibrocytes are increased in autoimmune conditions, including SSc $[72,73]$, and might play a part in tissue and vessel remodelling via multiple mechanisms, including the differentiation into activated myofibroblasts [71, 74].

Macrophages are attracting increasing attention for their role in the SSc (for recent excellent reviews, see $[75,76]$ ). A detailed description of the role of macrophages in promoting and sustaining SSc vasculopathy is outside the scope of this work. However, several evidences support the contention that the recognition of endogenous ligands in peripheral tissues of SSc patients by macrophages might be involved in feed-forward self-sustaining amplificatory circuits of vascular inflammation and fibrosis $[6,37,77]$.

\section{Clinical Impact of SSc Vasculopathy}

Although vasculopathy is present early and almost invariably during the course of SSc, clinical complications are traditionally classified mainly within either the fibrotic or the vascular components of the disease (Table 1). This classification is mainly based on histology and does not take into account the possible role of vascular inflammation and of vasculopathy in driving the fibrotic component of the disease.

Despite the fact that therapeutic improvements have changed the relative impact of SSc complications on patients' prognosis [78] SSc vasculopathy, in terms of pulmonary arterial hypertension $(\mathrm{PAH})$, heart involvement, and scleroderma renal crisis (SRC), still represents the first cause of diseaserelated mortality. Therapeutic targets are different in the vascular complications of SSc, suggesting that the pathogenesis of these conditions only partially overlaps. SRC prognosis has fortunately much improved since the recognition of the therapeutic role of ACE inhibitors [79]. SRC is typically characterized by malignant hypertension and rapidly progressive renal failure. Organ dysfunction (hearth failure, encephalopathy, and microangiopathic haemolytic anaemia) frequently coexist [80]. Histology shows onionskin-like lesions and fibrotic intimal sclerosis, with possible adventitial fibrosis and intravascular thrombosis [81]. Pathophysiology of SSc hearth involvement is complex and heterogeneous, but vasculopathy is believed to be the most frequent mechanism, resulting in focal and patchy myocardial ischemia and consequent fibrosis with either systolic or diastolic dysfunction [82].

\section{Pulmonary Arterial Hypertension}

Pulmonary hypertension $(\mathrm{PH})$ is defined as an elevated mean pulmonary arterial pressure $(\mathrm{mPAP}) \geq 25 \mathrm{mmHg}$ at rest [83]. PH is frequent in SSc and can be associated with 
TABLE 1: Most prominent fibrotic and vascular complications of SSc.

\begin{tabular}{ll}
\hline $\begin{array}{l}\text { Fibrotic } \\
\text { complications }\end{array}$ & Vascular complications \\
\hline Skin fibrosis & Raynaud phenomenon \\
\hline Lung fibrosis & Ischemic ulcers \\
\hline & Acral ischaemia/necrosis \\
& Gastral antral vascular ectasia (GAVE) \\
and gastrointestinal telangiectasias \\
involvement & Scleroderma renal crisis \\
& Heart involvement \\
& Pulmonary arterial hypertension \\
\hline
\end{tabular}

lung and hearth involvement or thromboembolic disease. Pulmonary arterial hypertension (PAH) is a disease characterized by progressive obliterative vasculopathy involving the distal pulmonary circulation, the distal pulmonary arteries in particular [83]. Progressive precapillary $\mathrm{PH}$ (i.e., $\mathrm{PH}$ with a pulmonary capillary wedge pressure $\leq 15 \mathrm{mmHg}$ and pulmonary vascular resistance $>3$ Wood Units) defines PAH. This results in progressive right heart failure [84], with a median survival without therapy of about 2.8 years from diagnosis [85]. SSc is one of the main causes of PAH [83]. Currently, PAH and interstitial lung disease represent the first causes of disease-related mortality in SSc patients. SScassociated PAH (SSc-PAH) has a prevalence between 10 and $12 \%$ of SSc patients and may occur even many years after the diagnosis [86]. SSc-PAH is associated with limited scleroderma, presence of anti-U3RNP autoantibodies, lateonset disease, multiple telangiectasias, digital ulcers, and worsening lung diffusion [86].

Mortality of SSc-PAH is worse than mortality of idiopathic PAH $[87,88]$. Early detection is therefore fundamental but remains challenging. Symptoms are caused by heart failure or worsening respiratory function and occur late during disease course. The diagnosis is not based on the direct identification of the lung vasculopathy but on the indirect evaluation of its hemodynamic impact, which can be definitively assessed with right heart catheterisation only, when the lung vascular reserve is already substantially compromised [89].

With the exception of a small group of patients with hereditary or idiopathic PAH responding to calcium channel blocker vasodilators, structural remodelling of the lung microcirculation is substantial. Currently available therapies for PAH antagonise endothelin-1 (ET-1) receptors increase concentrations of prostacyclin or its analogues or increase cyclic GMP in the lung vasculature antagonising phosphodiesterase-5. All these agents are believed to target both the vasoconstriction and the remodelling observed in the lung vasculature. However, patients with SSc-PAH have a poorer response to therapies, in comparison with other PAH subgroups [88], and up-front combination regimens of oral agents antagonising ET-1 receptors and phosphodiesterase-5 may provide a more effective intervention $[90,91]$. Autoimmunity with unrelenting inflammatory responses and more severe vessel and cardiac involvement might account for the poorer response to therapy of patients with SSc-PAH as compared to those with idiopathic PAH [88].

Histology of PAH is reminiscent of other small vessel vasculopathies, such as SSc. An obliterative and onionskin-like intimal and medial thickening is the pivotal finding. Intravascular thrombosis is frequent, and perivascular inflammation is observed. Muscularisation of small arteries as well as perivascular inflammation is typical. Endothelial cells may have a disorganised growth within the lumen of remodelled vessels, to form the so-called plexiform lesions [92]. SSc$\mathrm{PAH}$ pathology is similar, with more abundant inflammatory infiltrates and more frequent concomitant involvement of the venous compartment of the lung circulation [93].

Mechanisms underlying these changes are poorly understood. Similar histologic features of remodelled arteries and intimal hyperplasia are not exclusive of SSc but are believed to be a stereotyped vascular response to many types of injuries. Large-vessel vasculitides such as Takayasu arteritis [94] and giant cell arteritis [95] are inflammatory conditions in which arterial remodelling and intimal hyperplasia play a central role. Similarly to SSc, in Takayasu arteritis the progression in vascular stenoocclusions and the intensity of systemic inflammation poorly correlate [96-98]. Further studies are required to verify whether molecular events regulating cell plasticity in the SSc vessel walls might have a role in macrovascular diseases.

Increased numbers of cells expressing alpha-smooth muscle actin (alpha-SMA) are a nearly universal finding in the remodelled artery. Resident smooth muscle cells have been traditionally regarded as the predominant source of the newly appearing alpha-SMA-expressing cells. However, rapidly emerging experimental evidence suggests that other sources might play a role. We will briefly discuss below the possible contribution of the Endothelial to Mesenchymal Transition (EndoMT) and the evidence supporting a role of transforming growth factor-beta, Wnt, and Notch signaling in this process.

\section{EndoMT and TGF- $\beta$}

EndoMT refers to a transdifferentiation process in which endothelial cells downregulate the expression of endothelial markers, such as CD31 and vascular endothelial cadherin (VE-cadherin), acquiring a mesenchymal/myofibroblast phenotype, which is characterized by the expression of SMA, collagen type I (Col I), together with Twist 1, a specific marker of mesenchymal transition [74, 99].

EndoMT has emerged as a player in the pathogenesis of tissue fibrosis in various diseases, including diabetic nephropathy, cardiac fibrosis, intestinal fibrosis, portal hypertension, and PAH [100]. Experimental evidence supports a role of EndoMT in SSc as well [100-102]. Of importance, lung tissues of patients with interstitial lung disease associated with SSc have been elegantly shown to contain cells that simultaneously express EC-specific and mesenchymal proteins and transcripts, demonstrating that EndoMT actually occurs in target organs of the disease [103]. EndoMT could contribute, under the action of signals generated by inflammatory leukocytes recruited and activated into the 
perivascular tissues, to the conversion of endothelial cells into activated myofibroblasts, that is, cells responsible for the formation of scar tissue and for fibrosis [74, 99]. Thus, EndoMT would causally connect two hallmarks of SSc, the aberrant fibrogenesis and the persistent endothelial injury. TGF- $\beta$, a cytokine involved in embryogenesis, cellular differentiation, development, and inflammatory response, plays a role in fibrotic diseases by stimulating the production of collagens and other ECM components and by inhibiting the expression of various relevant metalloproteinases. TGF- $\beta$ is in particular a central cytokine in SSc [10]. TGF- $\beta$-regulated genes are expressed in the skin and the lung of patients with SSc and the extent of the cytokine expression correlates with the disease activity [10]. Moreover, mutations in the TGF$\beta$-sensing ALK-1 signaling pathway cause familial PAH and hereditary haemorrhagic telangiectasia, indicating a role of TGF- $\beta$ signaling in both SSc vasculopathy and fibrosis [10].

TGF- $\beta$ is able to induce plasticity in endothelial cells, committing them toward a fibrogenic fate. The process involves the acquisition of a mesenchymal progenitor multipotent status and is characterized by the transient expression of PDGFR $\alpha$ mRNA, by the increase of the mesenchymal markers expression (such as $\alpha$-SMA and Col I), and by the reduction of endothelial markers expression, CD31 and Tie 1 [104]. Li and Jimenez in 2011 observed in primary mouse pulmonary ECs the ability of TGF- $\beta$ to induce $\alpha$-SMA and type I collagen expression together with an inhibition of VEcadherin. These effects were associated with an increased Snail-1 expression, involving the c-Abl tyrosine kinase and protein kinase $\mathrm{C} \delta(\mathrm{PKC} \delta)$ activity [105].

\section{Wnt}

The Wnt proteins comprise a family of glycoproteins that via canonical and noncanonical intracellular signaling pathways play crucial roles during embryonic development. Wnt proteins and pathways have been also implicated in the pathogenesis of fibrotic diseases, including SSc [106-108]. TGF$\beta$ activates the canonical Wnt pathway, and multiple genes involved in tissue repair and in fibrosis are transcriptional targets of Wnt/ $\beta$-catenin [109]. Transcriptional analysis of primary alveolar epithelial type II (ATII) cells from patients with idiopathic pulmonary fibrosis (IPF) revealed an elevated expression of genes coding for Wnt ligands, receptors, regulators, and targets $[110,111]$. Other studies provided evidence of an increased Wnt expression and activity in the skin and the blood of patients with SSc [112]. Nuclear $\beta$-catenin, a marker of active canonical Wnt signaling, was strongly upregulated in the lung of patients with SSc-associated fibrosis [106]. Wnt3a could be implicated in the modulation of EndoMT in human dermal microvascular endothelial cells via the reduction of vascular endothelial cadherin mRNA expression and induction of vimentin and slug mRNA expression [113].

\section{Notch-Jagged}

The Notch signaling is also a fundamental pathway governing development. Notch receptors and their ligands have been located in the vascular system. Notch activation in endothelial cells results in morphological, phenotypic, and functional changes consistent with mesenchymal transformation. These changes are correlated with EndoMT, including downregulation of endothelial markers, upregulation of mesenchymal markers, and migration toward platelet-derived growth factor-BB. Notch and TGF- $\beta$ signaling synergistically induce the Snail expression in endothelial cells. Notch activation inhibits TGF- $\beta /$ Smad1 and TGF- $\beta /$ Smad 2 signaling pathways by decreasing the expression of Smad1 and Smad2 and their target genes. In contrast, Notch increases Smad3 mRNA expression and protein half-life and regulates the expression of TGF- $\beta / \mathrm{Smad} 3$ target genes in a gene-specific manner [114].

Notch signaling appears to be activated in the skin of patients with SSc, with overexpression of the ligand, jagged-1. This appears to be a nonredundant event in fibrogenesis, since genetic or pharmacological interference with this pathway inhibited the development of fibrosis in experimental animals, interfering with the generation of autoantibodies as well [115]. Thus, data in the literature suggest that the Notch pathway is correlated with EndoMT and that the same pathway is deregulated in SSc. However direct experimental evidence of Notch involvement in the modulation of EndoMT in SSc is so far missing.

\section{Endothelin 1}

Endothelin-1 (ET-1), a 21-residue peptide, is a potent vasoconstrictor. ET-1 regulates the vascular tone through interaction with endothelin receptors A (ETRA) and B (ETRB), prompts fibrogenesis, and possibly contributes to the vessel's instability and capillary rarefaction during SSc. Some in vitro evidence suggests that ET-1 might promote EndoMT on ECs isolated from SSc patients and macitentan, a dual endothelin-1 receptor antagonist, blocks the EndoMT induced in vitro by the combination of TGF- $\beta$ and ET-1 [116]. The actual relevance of these in vitro observations for the SSc vasculopathy remains to be established. For example, in vitro studies supported an antifibrotic effect of the ET-1 receptor antagonist, bosentan, which however was not consistent upon treatment of SSc patients with PAH (e.g., see [117]).

\section{Interferon}

Interferon has also been studied in the setting of EndoMT. IFN- $\alpha$ appears to downregulate while IFN- $\gamma$ appears to upregulate $\alpha$-SMA, CTGF, ET-1, and TGF $\beta 2$ expression in human dermal microvascular endothelial cells. In this in vitro experimental setting, the blockade of TGF $\beta$ signaling normalized IFN- $\gamma$-mediated changes in Fli-1, VE-cadherin, CTGF, and ET-1 levels, whereas the upregulation of $\alpha$ SMA and TGF $\beta 2$ was not affected. IFN $-\gamma$ also induced the expression of selected genes related to EndoMT, including Snail-1, FN1, PAI1, TWIST1, STAT3, RGS2, and components of the Wnt pathway [118]. 


\section{MicroRNAs}

MicroRNAs (miRNAs) consist of a class of small endogenous noncoding RNAs, approximately 22 nucleotides long, able to regulate posttranscriptionally gene expression. A single miRNA can modulate hundreds of target genes by suppressing translation, mediating mRNA segmentation, or causing RNA destabilization. On the other hand, multiple miRNAs can cooperate to regulate the expression of a single target gene. miRNAs might be involved in the natural history of SSc. A downregulation of miRNAs involved in the suppression of fibrosis (such as miR-29a, miR-196a, and miR-150) has been reported in SSc patients [119]. Upregulation of miRNAs able to induce the CollAl expression (such as miR-2lb) or other ECM molecules (miR-92a) has also been reported [120]. Conversely, miR-7, a miRNA with a role in the suppression of fibrosis, is upregulated in SSc fibroblasts possibly because of a negative feedback loop, associated with thrombospondin-2 upregulation [121].

TGF- $\beta$ significantly increased miR-21 expression in endothelial cells and induced EndoMT. Mechanistically, miR21 acts on phosphatase and tensin homolog in endothelial cells, favoring the activation of the Akt pathway [122]. A miRNA array on mouse cardiac endothelial cells and EndoMT-derived fibroblast-like cells revealed that miR125b, Let-7c, Let-7g, miR-21, miR-30b, and miR-195 were significantly elevated during EndoMT, while levels of several miRNAs including miR-122a, miR-127, miR-196, and miR375 were significantly downregulated [123]. Some of these signals, such as the miR-125b, might be directly implicated in the fibroblast-to-myofibroblast transition [124]. Although miRNA modulation appears to be an interesting field that might shed light on biological events occurring in SSc, little experimental evidence supports so far the contention that miRNA modulation actually occurs in endothelial cells of SSc patients. Moreover, like for other epigenetic regulations that have been implicated in the pathogenesis of SSc, their causal role in the various disease features remains elusive [125]. Specifically, it remains to be seen whether miRNA modulation reflects ongoing EndoMT, or it is a necessary condition to begin or effectively conclude the process.

\section{Oxidative Stress and EndoMT}

Oxidative stress mediated by reactive oxygen species (ROS) plays a role in various features of SSc [12, 66, 126, 127], possibly including senescence-correlated changes of SSc fibroblasts [128] and of bone marrow-derived mesenchymal stem cells of SSc patients, which express markers of early senescence and have an impaired ability to differentiate into endothelial cells [129]. Defective function of endothelial progenitor cells might contribute to the defective angiogenesis typical of the disease [13]. The NADPH oxidase (NOX) family of membraneassociated enzymes catalyzes the reduction of oxygen to form ROS. NOX4 in particular has a key role in the establishment and maintenance of tissue fibrosis. Several signals involved in SSc pathogenesis, including TGF- $\beta$, PDGF, and ET-1, modulate the expression of NOX and of NOX4 in particular [130]. Oxidative stress also induces the conversion of ECs into myofibroblasts via a mechanism possibly depending on ALK5/Smad3/NF- $\kappa$ B pathway [126].

\section{Shear Stress}

Uniform laminar shear stress (LSS) has anti-inflammatory and anticoagulant effects on ECs [131]. Conversely, EndoMT might be implicated in the fibroproliferative vascular disease and might be modulated by shear stress in a ERK5-dependent manner [131]. Prolonged exposure of EC to LSS results in sustained activation of p53 and in growth arrest [132]. KLF4 physically interacts with p53 in synergistic activation of p21, indicating interaction between $\mathrm{p} 53$ and ERK5 signaling pathways. Activation of ERK5 thus not only inhibits mesenchymal transition of EC, but also might be the key to reversal of the transition [131].

\section{EMT in SSc}

EMT is a process in which adhesive properties and polarity of epithelial cells are modified, with decreased expression of epithelial markers, including E-cadherin and Zo-1. In contrast expression of mesenchymal markers, such as vimentin and fibronectin, is upregulated [133] and matrix metalloproteinases (MMPs) are generated including MMP-2 and MMP9, which degrade collagen IV, the main component of the basement membrane, and aid the development of a migratory phenotype. The retained plasticity of pulmonary and renal epithelial cells and their ability to contribute directly to human fibrotic disease via EMT are well defined $[134,135]$. In vitro data suggest the involvement of TGF- $\beta$ and TNF- $\alpha$ synergic activity in driving EMT of primary keratinocytes, in a Smad-dependent manner. The use of specific Smad inhibitors could prevent EMT but more importantly can also reverse established EMT open to a new potential therapeutic intervention [133]. SSc keratinocytes exhibit a phenotype normally associated with tissue repair, including phosphorylation profiles indicative of TGF- $\beta$ signaling, with increased phosphorylated Smad2/3 nuclear translocation [136].

An important role in the EMT during SSc is also played by the lacking activity of Fli-1. The transcription factor Fli1, a member of the Ets transcription factor family, is epigenetically suppressed in SSc skin and SSc dermal fibroblasts and may represent such a predisposing factor for SSc [137]. Fli-1 expression is decreased in nonlesional SSc skin in various cell types, including dermal fibroblasts, endothelial cells, and perivascular inflammatory cells, suggesting that downregulation of Fli-1 is an early event preceding the development of fibrosis. The factors that might be involved in the downregulation of Fli- 1 include TGF- $\beta$ and interferon- $\gamma$, in addition to epigenetic mechanisms, and recent data suggest a new in vivo model to study the SSc phenotype in various cell types [138]. Indeed, bleomycin-induced skin fibrosis in Fli- ${ }^{+/-}$mice highlights alterations of dermal fibroblasts, endothelial cells, and macrophages reminiscent of the human disease, suggesting a new promising tool for the in vivo study of SSc [138]. 


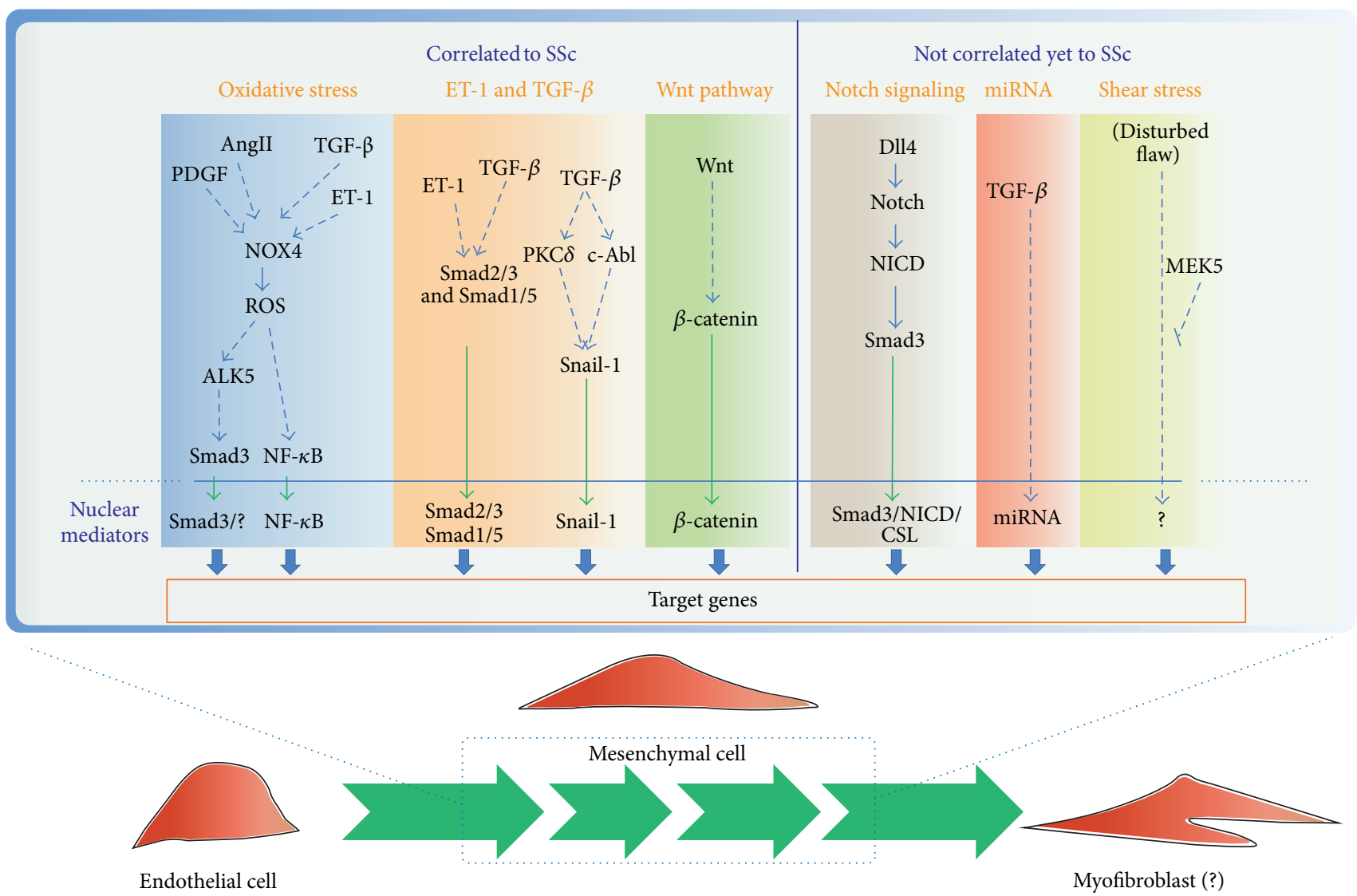

FIGURE 2: Pathways involved in the EndoMT. The scheme summarized the putative pathways involved in the EndoMT highlighting which are already correlated or not with SSc. The activation of specific nuclear mediator leads to activation of target genes that are correlated with the increase of mesenchymal markers (such as Col I, $\alpha$-SMA, and Twist 1) and/or decrease of endothelial markers (such as CD31, VE-Cad, and Fli-1). The activation of these pathways could lead endothelial cells to acquire initially mesenchymal characteristics and later on to acquire myofibroblastic features.

\section{Conclusions}

A failure of various intermingled homeostatic programs accounts for the complex phenotype of SSc patients. Defective homeostatic processes are governed by interacting signaling pathways, most of which are involved in the regulation of the vascular cell plasticity (Figure 2). Although much new information has been obtained on the mesenchymal transition of endothelial and epithelial cells and on the transition from fibroblasts to myofibroblasts over the past few years, many issues still require characterization, including the actual extent to which mesenchymal transition occurs in SSc patients. The contention that cell plasticity causally links the generalized vascular inflammation and remodelling with the fibrosis associated with SSc has not been formally demonstrated. In case it was, the molecular regulation underlying the substantially variable fibrosis (generalized versus limited) which characterizes each single patient would remain to be established. Moreover the contribution of autoimmunity in the process, which is felt to be important, remains elusive. New targets for molecular treatments are being identified. These discoveries may lead to profound advances in therapies for SSc and possibly for other persistent fibrotic and inflammatory diseases.

\section{Competing Interests}

The authors declare that they have no competing interests.

\section{Authors' Contributions}

Pier Andrea Nicolosi and Enrico Tombetti equally contributed to the paper.

\section{References}

[1] S. Bhattacharyya, J. Wei, and J. Varga, "Understanding fibrosis in systemic sclerosis: shifting paradigms, emerging opportunities," Nature Reviews Rheumatology, vol. 8, no. 1, pp. 42-54, 2012.

[2] F. M. Wigley, "Vascular disease in scleroderma," Clinical Reviews in Allergy and Immunology, vol. 36, no. 2-3, pp. 150175, 2009.

[3] L. A. Saketkoo and O. Distler, "Is there evidence for vasculitis in systemic sclerosis," Current Rheumatology Reports, vol. 14, no. 6, pp. 516-525, 2012.

[4] G. Farina, M. York, C. Collins, and R. Lafyatis, "dsRNA activation of endothelin-1 and markers of vascular activation in endothelial cells and fibroblasts," Annals of the Rheumatic Diseases, vol. 70, no. 3, pp. 544-550, 2011. 
[5] S. Lenna, A. G. Farina, V. Martyanov et al., "Increased expression of endoplasmic reticulum stress and unfolded protein response genes in peripheral blood mononuclear cells from patients with limited cutaneous systemic sclerosis and pulmonary arterial hypertension," Arthritis and Rheumatism, vol. 65, no. 5, pp. 1357-1366, 2013.

[6] G. Stifano, A. J. Affandi, A. L. Mathes et al., "Chronic Tolllike receptor 4 stimulation in skin induces inflammation, macrophage activation, transforming growth factor beta signature gene expression, and fibrosis," Arthritis Research and Therapy, vol. 16, article R136, 2014.

[7] L. van Bon, A. J. Affandi, J. Broen et al., "Proteome-wide analysis and CXCL4 as a biomarker in systemic sclerosis," New England Journal of Medicine, vol. 370, no. 5, pp. 433-443, 2014.

[8] S. Bhattacharyya and J. Varga, "Emerging roles of innate immune signaling and toll-like receptors in fibrosis and systemic sclerosis," Current Rheumatology Reports, vol. 17, article 474, 2015.

[9] S. Guiducci, O. Distler, J. H. Distler, and M. Matucci-Cerinic, "Mechanisms of vascular damage in SSc_implications for vascular treatment strategies," Rheumatology, vol. 47, supplement 5, pp. v18-v20, 2008.

[10] R. Lafyatis, "Transforming growth factor $\beta$-at the centre of systemic sclerosis," Nature Reviews Rheumatology, vol. 10, no. 12, pp. 706-719, 2014.

[11] M. Cutolo and V. Smith, "State of the art on nailfold capillaroscopy: a reliable diagnostic tool and putative biomarker in rheumatology?" Rheumatology, vol. 52, no. 11, Article ID ket153, pp. 1933-1940, 2013.

[12] A. Gabrielli, E. V. Avvedimento, and T. Krieg, "Scleroderma," The New England Journal of Medicine, vol. 360, no. 19, pp. 19892003, 2009.

[13] M. Matucci-Cerinic, B. Kahaleh, and F. M. Wigley, "Review: evidence that systemic sclerosis is a vascular disease," Arthritis and Rheumatism, vol. 65, no. 8, pp. 1953-1962, 2013.

[14] C. Beyer, G. Schett, S. Gay, O. Distler, and J. H. W. Distler, "Hypoxia. Hypoxia in the pathogenesis of systemic sclerosis," Arthritis Research \& Therapy, vol. 11, no. 2, article 220, 2009.

[15] C. Dees, A. Akhmetshina, P. Zerr et al., "Platelet-derived serotonin links vascular disease and tissue fibrosis," Journal of Experimental Medicine, vol. 208, no. 5, pp. 961-972, 2011.

[16] T. C. Barnes, D. G. Spiller, M. E. Anderson, S. W. Edwards, and R. J. Moots, "Endothelial activation and apoptosis mediated by neutrophil-dependent interleukin 6 trans-signalling: a novel target for systemic sclerosis?" Annals of the Rheumatic Diseases, vol. 70, no. 2, pp. 366-372, 2011.

[17] A. Zarbock, T. Kempf, K. C. Wollert, and D. Vestweber, "Leukocyte integrin activation and deactivation: novel mechanisms of balancing inflammation," Journal of Molecular Medicine, vol. 90, no. 4, pp. 353-359, 2012.

[18] J. N. Fleming and S. M. Schwartz, "The pathology of scleroderma vascular disease," Rheumatic Disease Clinics of North America, vol. 34, no. 1, pp. 41-55, 2008.

[19] B. Kahaleh, "Vascular disease in scleroderma: mechanisms of vascular injury," Rheumatic Disease Clinics of North America, vol. 34, no. 1, pp. 57-71, 2008.

[20] M. Trojanowska, "Cellular and molecular aspects of vascular dysfunction in systemic sclerosis," Nature Reviews Rheumatology, vol. 6, no. 8, pp. 453-460, 2010.

[21] M. Manetti, S. Guiducci, E. Romano et al., "Overexpression of VEGF165b, an inhibitory splice variant of vascular endothelial growth factor, leads to insufficient angiogenesis in patients with systemic sclerosis," Circulation Research, vol. 109, no. 3, pp. el4e26, 2011.

[22] C. Mazzotta, E. Romano, C. Bruni et al., "PlexinD1/Semaphorin 3E pathway may contribute to dysregulation of vascular tone control and defective angiogenesis in systemic sclerosis," Arthritis Research and Therapy, vol. 17, no. 1, article 221, 2015

[23] E. Romano, I. Chora, M. Manetti et al., "Decreased expression of neuropilin-1 as a novel key factor contributing to peripheral microvasculopathy and defective angiogenesis in systemic sclerosis," Annals of the Rheumatic Diseases, 2015.

[24] A. L. Herrick, "The pathogenesis, diagnosis and treatment of Raynaud phenomenon," Nature Reviews Rheumatology, vol. 8, no. 8, pp. 469-479, 2012.

[25] A. E. Postlethwaite and T. M. Chiang, "Platelet contributions to the pathogenesis of systemic sclerosis," Current Opinion in Rheumatology, vol. 19, no. 6, pp. 574-579, 2007.

[26] J. D. Pauling, V. B. O'donnell, and N. J. Mchugh, "The contribution of platelets to the pathogenesis of Raynaud's phenomenon and systemic sclerosis," Platelets, vol. 24, no. 7, pp. 503-515, 2013.

[27] G. A. Ramirez, S. Franchini, P. Rovere-Querini, M. G. Sabbadini, A. A. Manfredi, and N. Maugeri, "The role of platelets in the pathogenesis of systemic sclerosis," Frontiers in Immunology, vol. 3, article 160, 2012.

[28] A. Solanilla, J. Villeneuve, P. Auguste et al., "The transport of high amounts of vascular endothelial growth factor by blood platelets underlines their potential contribution in systemic sclerosis angiogenesis," Rheumatology, vol. 48, no. 9, pp. 1036$1044,2009$.

[29] M. M. Cerinic, G. Valentini, G. G. Sorano et al., "Blood coagulation, fibrinolysis, and markers of endothelial dysfunction in systemic sclerosis," Seminars in Arthritis and Rheumatism, vol. 32, no. 5, pp. 285-295, 2003.

[30] A. Rouhiainen, S. Imai, H. Rauvala, and J. Parkkinen, "Occurrence of amphoterin (HMG1) as an endogenous protein of human platelets that is exported to the cell surface upon platelet activation," Thrombosis and Haemostasis, vol. 84, no. 6, pp. 10871094, 2000.

[31] P. Rovere-Querini, A. Capobianco, P. Scaffidi et al., "HMGB1 is an endogenous immune adjuvant released by necrotic cells," EMBO Reports, vol. 5, no. 8, pp. 825-830, 2004.

[32] H. E. Harris, U. Andersson, and D. S. Pisetsky, "HMGB1: a multifunctional alarmin driving autoimmune and inflammatory disease," Nature Reviews Rheumatology, vol. 8, no. 4, pp. 195-202, 2012.

[33] H. Yang, H. Wang, S. S. Chavan, and U. Andersson, "High mobility group box protein 1 (HMGB1): the prototypical endogenous danger molecule," Molecular Medicine, vol. 21, pp. S6-S12, 2015.

[34] M. E. Bianchi and A. A. Manfredi, "Dangers in and out," Science, vol. 323, no. 5922, pp. 1683-1684, 2009.

[35] A. Castiglioni, V. Canti, P. Rovere-Querini, and A. A. Manfredi, "High-mobility group box 1 (HMGB1) as a master regulator of innate immunity," Cell and Tissue Research, vol. 343, no. 1, pp. 189-199, 2011.

[36] U. Andersson and K. J. Tracey, "HMGB1 is a therapeutic target for sterile inflammation and infection," Annual Review of Immunology, vol. 29, pp. 139-162, 2011.

[37] M. E. Bianchi and A. A. Manfredi, "How macrophages ring the inflammation alarm," Proceedings of the National Academy of 
Sciences of the United States of America, vol. 111, no. 8, pp. 28662867, 2014.

[38] M. Zhang, Y. Guo, H. Fu et al., "Chop deficiency prevents UUOinduced renal fibrosis by attenuating fibrotic signals originated from Hmgb1/TLR4/NFkB/IL-1 $\beta$ signaling," Cell Death and Disease, vol. 6, Article ID e1847, 2015.

[39] Z. Zhu and X. Hu, "HMGB1 induced endothelial permeability promotes myocardial fibrosis in diabetic cardiomyopathy," International Journal of Cardiology, 2015.

[40] L.-C. Li, D.-L. Li, L. Xu et al., "High-mobility group box 1 mediates epithelial-to-mesenchymal transition in pulmonary fibrosis involving transforming growth factor- $\beta 1 / \mathrm{Smad} 2 / 3$ signaling," Journal of Pharmacology and Experimental Therapeutics, vol. 354, no. 3, pp. 302-309, 2015.

[41] L.-C. Li, J. Gao, and J. Li, "Emerging role of HMGB1 in fibrotic diseases," Journal of Cellular and Molecular Medicine, vol. 18, no. 12, pp. 2331-2339, 2014.

[42] K. Hayakawa, L.-D. D. Pham, Z. S. Katusic, K. Arai, and E. H. Lo, "Astrocytic high-mobility group box 1 promotes endothelial progenitor cell-mediated neurovascular remodeling during stroke recovery," Proceedings of the National Academy of Sciences of the United States of America, vol. 109, no. 19, pp. 75057510, 2012.

[43] L. Campana, F. Santarella, A. Esposito et al., "Leukocyte HMGB1 is required for vessel remodeling in regenerating muscles," Journal of Immunology, vol. 192, no. 11, pp. 5257-5264, 2014.

[44] A. Yoshizaki, K. Komura, Y. Iwata et al., "Clinical significance of serum HMGB-1 and sRAGE levels in systemic sclerosis: association with disease severity," Journal of Clinical Immunology, vol. 29, no. 2, pp. 180-189, 2009.

[45] N. Maugeri, S. Franchini, L. Campana et al., "Circulating platelets as a source of the damage-associated molecular pattern HMGB1 in patients with systemic sclerosis," Autoimmunity, vol. 45, no. 8, pp. 584-587, 2012.

[46] N. Maugeri, P. Rovere-Querini, M. Baldini et al., "Oxidative stress elicits platelet/leukocyte inflammatory interactions via HMGB1: a Candidate for microvessel injury in sytemic sclerosis," Antioxidants and Redox Signaling, vol. 20, no. 7, pp. 10601074, 2014.

[47] N. Maugeri, L. Campana, M. Gavina et al., "Activated platelets present high mobility group box 1 to neutrophils, inducing autophagy and promoting the extrusion of neutrophil extracellular traps," Journal of Thrombosis and Haemostasis, vol. 12, no. 12, pp. 2074-2088, 2014.

[48] S. Guiducci, J. H. W. Distler, A. Jüngel et al., "The relationship between plasma microparticles and disease manifestations in patients with systemic sclerosis," Arthritis and Rheumatism, vol. 58, no. 9, pp. 2845-2853, 2008.

[49] C. Oyabu, A. Morinobu, D. Sugiyama et al., "Plasma plateletderived microparticles in patients with connective tissue diseases," Journal of Rheumatology, vol. 38, no. 4, pp. 680-684, 2011.

[50] J. H. W. Distler, A. Akhmetshina, C. Dees et al., "Induction of apoptosis in circulating angiogenic cells by microparticles," Arthritis and Rheumatism, vol. 63, no. 7, pp. 2067-2077, 2011.

[51] D. S. Pisetsky, A. J. Ullal, J. Gauley, and T. C. Ning, "Microparticles as mediators and biomarkers of rheumatic disease," Rheumatology, vol. 51, no. 10, pp. 1737-1746, 2012.

[52] L. V. Iversen, S. Ullman, O. Østergaard et al., "Cross-sectional study of soluble selectins, fractions of circulating microparticles and their relationship to lung and skin involvement in systemic sclerosis," BMC Musculoskeletal Disorders, vol. 16, article 191, 2015.
[53] E. Venereau, M. Casalgrandi, M. Schiraldi et al., "Mutually exclusive redox forms of HMGB1 promote cell recruitment or proinflammatory cytokine release," Journal of Experimental Medicine, vol. 209, no. 9, pp. 1519-1528, 2012.

[54] G. Hoppe, K. E. Talcott, S. K. Bhattacharya, J. W. Crabb, and J. E. Sears, "Molecular basis for the redox control of nuclear transport of the structural chromatin protein Hmgbl," Experimental Cell Research, vol. 312, no. 18, pp. 3526-3538, 2006.

[55] E. Venereau, M. Schiraldi, M. Uguccioni, and M. E. Bianchi, "HMGB1 and leukocyte migration during trauma and sterile inflammation," Molecular Immunology, vol. 55, no. 1, pp. 76-82, 2013.

[56] L. Campana, L. Bosurgi, M. E. Bianchi, A. A. Manfredi, and P. Rovere-Querini, "Requirement of HMGB1 for stromal cellderived factor-1/CXCL12-dependent migration of macrophages and dendritic cells," Journal of Leukocyte Biology, vol. 86, no. 3, pp. 609-615, 2009.

[57] M. Vezzoli, P. Castellani, L. Campana et al., "Redox remodeling: a candidate regulator of HMGB1 function in injured skeletal muscle," Annals of the New York Academy of Sciences, vol. 1209, no. 1, pp. 83-90, 2010.

[58] M. Vezzoli, P. Castellani, G. Corna et al., "High-mobility group box 1 release and redox regulation accompany regeneration and remodeling of skeletal muscle," Antioxidants and Redox Signaling, vol. 15, no. 8, pp. 2161-2174, 2011.

[59] M. Schiraldi, A. Raucci, L. M. Muñoz et al., "HMGB1 promotes recruitment of inflammatory cells to damaged tissues by forming a complex with CXCL12 and signaling via CXCR4," The Journal of Experimental Medicine, vol. 209, no. 3, pp. 551-563, 2012.

[60] H. Kazama, J.-E. Ricci, J. M. Herndon, G. Hoppe, D. R. Green, and T. A. Ferguson, "Induction of immunological tolerance by apoptotic cells requires caspase-dependent oxidation of highmobility group box-1 protein," Immunity, vol. 29, no. 1, pp. 2132, 2008.

[61] D. Tang, R. Kang, H. J. Zeh, and M. T. Lotze, "High-mobility group box 1, oxidative stress, and disease," Antioxidants and Redox Signaling, vol. 14, no. 7, pp. 1315-1335, 2011.

[62] D. S. Pisetsky, J. Gauley, and A. J. Ullal, "HMGB1 and microparticles as mediators of the immune response to cell death," Antioxidants and Redox Signaling, vol. 15, no. 8, pp. 2209-2219, 2011.

[63] H. Yang, P. Lundbäck, L. Ottosson et al., "Redox modification of cysteine residues regulates the cytokine activity of high mobility group box-1 (HMGB1)," Molecular Medicine, vol. 18, no. 2, pp. 250-259, 2012

[64] P. Castellani, E. Balza, and A. Rubartelli, "Inflammation, DAMPs, tumor development, and progression: a vicious circle orchestrated by redox signaling," Antioxidants and Redox Signaling, vol. 20, no. 7, pp. 1086-1097, 2014.

[65] D. S. Pisetsky, "The translocation of nuclear molecules during inflammation and cell death," Antioxidants and Redox Signaling, vol. 20, no. 7, pp. 1117-1125, 2014.

[66] T. Spadoni, S. Svegliati Baroni, D. Amico et al., "A reactive oxygen species-mediated loop maintains increased expression of NADPH oxidases 2 and 4 in skin fibroblasts from patients with systemic sclerosis," Arthritis and Rheumatology, vol. 67, no. 6, pp. 1611-1622, 2015.

[67] G. A. Ramirez, N. Maugeri, M. G. Sabbadini, P. Rovere-Querini, and A. A. Manfredi, "Intravascular immunity as a key to systemic vasculitis: a work in progress, gaining momentum," 
Clinical and Experimental Immunology, vol. 175, no. 2, pp. 150166, 2014.

[68] G. A. Ramirez, P. Rovere-Querini, G. Sabbadini, and A. A. Manfredi, "Parietal and intravascular innate mechanisms of vascular inflammation," Arthritis Research and Therapy, vol. 17, article 16, 2015.

[69] S. Vogel, R. Bodenstein, Q. Chen et al., "Platelet-derived HMGB1 is a critical mediator of thrombosis," The Journal of Clinical Investigation, vol. 125, no. 12, pp. 4638-4654, 2015.

[70] I. Ahrens, Y. Chen, D. Topcic et al., "HMGB1 binds to activated platelets via the receptor for advanced glycation end products and is present in platelet rich human coronary artery thrombi," Thrombosis and Haemostasis, vol. 114, no. 5, pp. 994-1003, 2015.

[71] C. L. Galligan and E. N. Fish, "The role of circulating fibrocytes in inflammation and autoimmunity," Journal of Leukocyte Biology, vol. 93, no. 1, pp. 45-50, 2013.

[72] S. K. Mathai, M. Gulati, X. Peng et al., "Circulating monocytes from systemic sclerosis patients with interstitial lung disease show an enhanced profibrotic phenotype," Laboratory Investigation, vol. 90, no. 6, pp. 812-823, 2010.

[73] H. Sun, Y. Zhu, H. Pan et al., "Netrin-1 regulates fibrocyte accumulation in the decellularized fibrotic scleroderma lung microenvironment and in bleomycin induced pulmonary fibrosis," Arthritis \& Rheumatology, 2016.

[74] S. A. Jimenez and S. Piera-Velazquez, "Endothelial to mesenchymal transition (EndoMT) in the pathogenesis of Systemic Sclerosis-associated pulmonary fibrosis and pulmonary arterial hypertension. Myth or reality?" Matrix Biology, 2016.

[75] J. J. Chia and T. T. Lu, "Update on macrophages and innate immunity in scleroderma," Current Opinion in Rheumatology, vol. 27, no. 6, pp. 530-536, 2015.

[76] G. Stifano and R. B. Christmann, "Macrophage involvement in systemic sclerosis: do we need more evidence?" Current Rheumatology Reports, vol. 18, no. 1, article 2, 2016.

[77] A. L. Mathes, R. B. Christmann, G. Stifano, A. J. Affandi, T. R. Radstake et al., "Global chemokine expression in systemic sclerosis (SSc): CCL19 expression correlates with vascular inflammation in SSc skin," Annals of the Rheumatic Diseases, vol. 73, no. 10, pp. 1864-1872, 2014.

[78] V. D. Steen and T. A. Medsger, "Changes in causes of death in systemic sclerosis, 1972-2002," Annals of the Rheumatic Diseases, vol. 66, no. 7, pp. 940-944, 2007.

[79] V. D. Steen and T. A. Medsger Jr., "Long-term outcomes of scleroderma renal crisis," Annals of Internal Medicine, vol. 133, no. 8, pp. 600-603, 2000.

[80] M. Hudson, "Scleroderma renal crisis," Current Opinion in Rheumatology, vol. 27, no. 6, pp. 549-554, 2015.

[81] P. J. Cannon, M. Hassar, D. B. Case, W. J. Casarella, S. C. Sommers, and E. C. LeRoy, "The relationship of hypertension and renal failure in scleroderma (progressive systemic sclerosis) to structural and functional abnormalities of the renal cortical circulation," Medicine, vol. 53, no. 1, pp. 1-46, 1974.

[82] C. Meune, O. Vignaux, A. Kahan, and Y. Allanore, "Heart involvement in systemic sclerosis: evolving concept and diagnostic methodologies," Archives of Cardiovascular Diseases, vol. 103, no. 1, pp. 46-52, 2010.

[83] N. Galiè, M. Humbert, J. Vachiery et al., "2015 ESC/ERS Guidelines for the diagnosis and treatment of pulmonary hypertension," European Respiratory Journal, vol. 46, no. 4, pp. 903-975, 2015.
[84] A. Vonk-Noordegraaf, F. Haddad, K. M. Chin et al., "Right heart adaptation to pulmonary arterial hypertension: physiology and pathobiology," Journal of the American College of Cardiology, vol. 62, no. 25, pp. D22-D33, 2013.

[85] V. V. McLaughlin, K. W. Presberg, R. L. Doyle et al., "Prognosis of pulmonary arterial hypertension: ACCP evidence-based clinical practice guidelines," Chest, vol. 126, no. 1, pp. 78S-92S, 2004.

[86] S. Chatterjee, "Pulmonary hypertension in systemic sclerosis," Seminars in Arthritis and Rheumatism, vol. 41, no. 1, pp. 19-37, 2011.

[87] S. M. Kawut, D. B. Taichman, C. L. Archer-Chicko, H. I. Palevsky, and S. E. Kimmel, "Hemodynamics and survival in patients with pulmonary arterial hypertension related to systemic sclerosis," Chest, vol. 123, no. 2, pp. 344-350, 2003.

[88] M. R. Fisher, S. C. Mathai, H. C. Champion et al., "Clinical differences between idiopathic and scleroderma-related pulmonary hypertension," Arthritis and Rheumatism, vol. 54, no. 9, pp. 3043-3050, 2006.

[89] E. M. T. Lau, A. Manes, D. S. Celermajer, and N. Galié, “Early detection of pulmonary vascular disease in pulmonary arterial hypertension: time to move forward," European Heart Journal, vol. 32, no. 20, pp. 2489-2498, 2011.

[90] P. M. Hassoun, R. T. Zamanian, R. Damico et al., "Ambrisentan and tadalafil up-front combination therapy in sclerodermaassociated pulmonary arterial hypertension," American Journal of Respiratory and Critical Care Medicine, vol. 192, no. 9, pp. 1102-1110, 2015.

[91] N. Galie, J. A. Barbera, A. E. Frost et al., "Initial use of ambrisentan plus tadalafil in pulmonary arterial hypertension," The New England Journal of Medicine, vol. 373, no. 9, pp. 834844, 2015.

[92] E. Stacher, B. B. Graham, J. M. Hunt et al., "Modern age pathology of pulmonary arterial hypertension," American Journal of Respiratory and Critical Care Medicine, vol. 186, no. 3, pp. 261272, 2012.

[93] P. Dorfmüller, M. Humbert, F. Perros et al., "Fibrous remodeling of the pulmonary venous system in pulmonary arterial hypertension associated with connective tissue diseases," Human Pathology, vol. 38, no. 6, pp. 893-902, 2007.

[94] J. C. Mason, "Takayasu arteritis-advances in diagnosis and management," Nature Reviews Rheumatology, vol. 6, no. 7, pp. 406-415, 2010.

[95] C. M. Weyand and J. J. Goronzy, "Giant-cell arteritis and polymyalgia rheumatica," The New England Journal of Medicine, vol. 371, no. 1, pp. 50-57, 2014.

[96] E. Tombetti, S. Franchini, M. Papa, M. G. Sabbadini, and E. Baldissera, "Treatment of refractory Takayasu arteritis with tocilizumab: 7 Italian patients from a single referral center," The Journal of Rheumatology, vol. 40, no. 12, pp. 2047-2051, 2013.

[97] E. Tombetti, M. C. Di Chio, S. Sartorelli et al., "Systemic pentraxin-3 levels reflect vascular enhancement and progression in Takayasu arteritis," Arthritis Research and Therapy, vol. 16, article 479, 2014.

[98] E. Tombetti, M. C. Di Chio, S. Sartorelli et al., "Procalcitonin in takayasu arteritis," The Journal of Rheumatology, vol. 41, no. 7, pp. 1564-1566, 2014.

[99] J. S. Duffield, M. Lupher, V. J. Thannickal, and T. A. Wynn, "Host responses in tissue repair and fibrosis," Annual Review of Pathology: Mechanisms of Disease, vol. 8, pp. 241-276, 2013. 
[100] J. He, Y. Xu, D. Koya, and K. Kanasaki, "Role of the endothelialto-mesenchymal transition in renal fibrosis of chronic kidney disease," Clinical and Experimental Nephrology, vol. 17, no. 4, pp. 488-497, 2013.

[101] F. Rieder, S. P. Kessler, G. A. West et al., "Inflammation-induced endothelial-to-mesenchymal transition: a novel mechanism of intestinal fibrosis," The American Journal of Pathology, vol. 179, no. 5, pp. 2660-2673, 2011.

[102] R. Kramann, D. P. Dirocco, and B. D. Humphreys, "Understanding the origin, activation and regulation of matrix-producing myofibroblasts for treatment of fibrotic disease," Journal of Pathology, vol. 231, no. 3, pp. 273-289, 2013.

[103] F. A. Mendoza, S. Piera-Velazquez, J. L. Farber, C. FeghaliBostwick, and S. A. Jiménez, "Endothelial cells expressing endothelial and mesenchymal cell gene products in lung tissue from patients with systemic sclerosis-associated interstitial lung disease," Arthritis \& Rheumatism, vol. 68, no. 1, pp. 210-217, 2016.

[104] P. Pessina, Y. Kharraz, M. Jardí et al., "Fibrogenic cell plasticity blunts tissue regeneration and aggravates muscular dystrophy," Stem Cell Reports, vol. 4, no. 6, pp. 1046-1060, 2015.

[105] Z. Li and S. A. Jimenez, "Protein kinase C $\delta$ and c-Abl kinase are required for transforming growth factor $\beta$ induction of endothelial-mesenchymal transition in vitro," Arthritis and Rheumatism, vol. 63, no. 8, pp. 2473-2483, 2011.

[106] J. Wei, F. Fang, A. P. Lam et al., "Wnt/ $\beta$-catenin signaling is hyperactivated in systemic sclerosis and induces Smaddependent fibrotic responses in mesenchymal cells," Arthritis and Rheumatism, vol. 64, no. 8, pp. 2734-2745, 2012.

[107] C. Beyer, A. Schramm, A. Akhmetshina et al., " $\beta$-catenin is a central mediator of pro-fibrotic Wnt signaling in systemic sclerosis," Annals of the Rheumatic Diseases, vol. 71, no. 5, pp. 761-767, 2012.

[108] A. P. Lam, J. D. Herazo-Maya, J. A. Sennello et al., "Wnt coreceptor Lrp5 is a driver of idiopathic pulmonary fibrosis," American Journal of Respiratory and Critical Care Medicine, vol. 190, no. 2, pp. 185-195, 2014.

[109] A. Akhmetshina, K. Palumbo, C. Dees et al., "Activation of canonical Wnt signalling is required for TGF- $\beta$-mediated fibrosis," Nature Communications, vol. 3, article 735, 2012.

[110] V. Aumiller, N. Balsara, J. Wilhelm, A. Günther, and M. Königshoff, "WNT/ $\beta$-catenin signaling induces IL- $1 \beta$ expression by alveolar epithelial cells in pulmonary fibrosis," American Journal of Respiratory Cell and Molecular Biology, vol. 49, no. 1, pp. 96-104, 2013.

[111] M. Königshoff, N. Balsara, E.-M. Pfaff et al., "Functional Wnt signaling is increased in idiopathic pulmonary fibrosis," PLoS ONE, vol. 3, no. 5, Article ID e2142, 2008.

[112] R. Lemaire, G. Farina, J. Bayle et al., "Antagonistic effect of the matricellular signaling protein CCN3 on TGF- $\beta$ - and Wntmediated fibrillinogenesis in systemic sclerosis and Marfan syndrome," Journal of Investigative Dermatology, vol. 130, no. 6, pp. 1514-1523, 2010.

[113] W. J. Lee, J. H. Park, J. U. Shin et al., "Endothelial-tomesenchymal transition induced by Wnt 3 a in keloid pathogenesis," Wound Repair and Regeneration, vol. 23, no. 3, pp. 435442, 2015.

[114] Y. X. Fu, A. Chang, L. Chang et al., "Differential regulation of transforming growth factor $\beta$ signaling pathways by notch in human endothelial cells," The Journal of Biological Chemistry, vol. 284, no. 29, pp. 19452-19462, 2009.
[115] C. Beyer and J. H. W. Distler, "Morphogen pathways in systemic sclerosis," Current Rheumatology Reports, vol. 15, no. 1, article 299, 2013.

[116] P. Cipriani, P. Di Benedetto, P. Ruscitti et al., “The endothelialmesenchymal transition in systemic sclerosis is induced by endothelin- 1 and transforming growth factor- $\beta$ and may be blocked by macitentan, a dual endothelin-1 receptor antagonist," Journal of Rheumatology, vol. 42, no. 10, pp. 1808-1816, 2015.

[117] T. J. Corte, G. J. Keir, K. Dimopoulos et al., "Bosentan in pulmonary hypertension associated with fibrotic idiopathic interstitial pneumonia," American Journal of Respiratory and Critical Care Medicine, vol. 190, no. 2, pp. 208-217, 2014.

[118] I. Chrobak, S. Lenna, L. Stawski, and M. Trojanowska, "Interferon- $\gamma$ promotes vascular remodeling in human microvascular endothelial cells by upregulating endothelin (ET)-1 and transforming growth factor (TGF) $\beta 2$," Journal of Cellular Physiology, vol. 228, no. 8, pp. 1774-1783, 2013.

[119] H. Zhu, H. Luo, and X. Zuo, "MicroRNAs: their involvement in fibrosis pathogenesis and use as diagnostic biomarkers in scleroderma," Experimental and Molecular Medicine, vol. 45, no. 9, article e41, 2013.

[120] X. Deng, Y. Su, H. Wu et al., "The role of microRNAs in autoimmune diseases with skin involvement," Scandinavian Journal of Immunology, vol. 81, no. 3, pp. 153-165, 2015.

[121] I. Kajihara, M. Jinnin, K. Yamane et al., "Increased accumulation of extracellular thrombospondin-2 due to low degradation activity stimulates type I collagen expression in scleroderma fibroblasts," American Journal of Pathology, vol. 180, no. 2, pp. 703-714, 2012.

[122] R. Kumarswamy, I. Volkmann, V. Jazbutyte, S. Dangwal, D.H. Park, and T. Thum, "Transforming growth factor- $\beta$-induced endothelial-to-mesenchymal transition is partly mediated by microRNA-21," Arteriosclerosis, Thrombosis, and Vascular Biology, vol. 32, no. 2, pp. 361-369, 2012.

[123] A. K. Ghosh, V. Nagpal, J. W. Covington, M. A. Michaels, and D. E. Vaughan, "Molecular basis of cardiac endothelialto-mesenchymal transition (EndMT): differential expression of microRNAs during EndMT," Cellular Signalling, vol. 24, no. 5, pp. 1031-1036, 2012.

[124] V. Nagpal, R. Rai, A. T. Place et al., "MiR-125b is critical for fibroblast-to-myofibroblast transition and cardiac fibrosis," Circulation, vol. 133, no. 3, pp. 291-301, 2015.

[125] N. Altorok, N. Almeshal, Y. Wang, and B. Kahaleh, "Epigenetics, the holy grail in the pathogenesis of systemic sclerosis," Rheumatology, vol. 54, no. 10, pp. 1759-1770, 2015.

[126] I. Montorfano, A. Becerra, R. Cerro et al., "Oxidative stress mediates the conversion of endothelial cells into myofibroblasts via a TGF-betal and TGF-beta2-dependent pathway," Laboratory Investigation, vol. 94, no. 10, pp. 1068-1082, 2014.

[127] S. Piera-Velazquez and S. A. Jimenez, "Role of cellular senescence and NOX4-mediated oxidative stress in systemic sclerosis pathogenesis," Current Rheumatology Reports, vol. 17, no. 1, article 473, 2015.

[128] V. I. Dumit, V. Küttner, J. Käppler et al., "Altered MCM protein levels and autophagic flux in aged and systemic sclerosis dermal fibroblasts," Journal of Investigative Dermatology, vol. 134, no. 9, pp. 2321-2330, 2014.

[129] P. Cipriani, S. Guiducci, I. Miniati et al., "Impairment of endothelial cell differentiation from bone marrow-derived mesenchymal stem cells: new insight into the pathogenesis of 
systemic sclerosis," Arthritis and Rheumatism, vol. 56, no. 6, pp. 1994-2004, 2007.

[130] B. Eckes, P. Moinzadeh, G. Sengle, N. Hunzelmann, and T. Krieg, "Molecular and cellular basis of scleroderma," Journal of Molecular Medicine, vol. 92, no. 9, pp. 913-924, 2014.

[131] J. R. Moonen, E. S. Lee, M. Schmidt et al., "Endothelialto-mesenchymal transition contributes to fibro-proliferative vascular disease and is modulated by fluid shear stress," Cardiovascular Research, vol. 108, no. 3, pp. 377-386, 2015.

[132] K. Lin, P.-P. Hsu, B. P. Chen et al., "Molecular mechanism of endothelial growth arrest by laminar shear stress," Proceedings of the National Academy of Sciences of the United States of America, vol. 97, no. 17, pp. 9385-9389, 2000.

[133] D. O'Kane, M. V. Jackson, A. Kissenpfennig et al., "SMAD inhibition attenuates epithelial to mesenchymal transition by primary keratinocytes in vitro," Experimental Dermatology, vol. 23, no. 7, pp. 497-503, 2014.

[134] M. Zeisberg, C. Yang, M. Martino et al., "Fibroblasts derive from hepatocytes in liver fibrosis via epithelial to mesenchymal transition," The Journal of Biological Chemistry, vol. 282, no. 32, pp. 23337-23347, 2007.

[135] K. K. Kim, M. C. Kugler, P. J. Wolters et al., "Alveolar epithelial cell mesenchymal transition develops in vivo during pulmonary fibrosis and is regulated by the extracellular matrix," Proceedings of the National Academy of Sciences of the United States of America, vol. 103, no. 35, pp. 13180-13185, 2006.

[136] J. Nikitorowicz-Buniak, C. P. Denton, D. Abraham, and R. Stratton, "Partially evoked epithelial-mesenchymal transition (EMT) is associated with increased TGF $\beta$ signaling within lesional scleroderma skin," PLoS ONE, vol. 10, no. 7, Article ID e0134092, 2015.

[137] Y. Wang, P.-S. Fan, and B. Kahaleh, "Association between enhanced type I collagen expression and epigenetic repression of the FLI1 gene in scleroderma fibroblasts," Arthritis and Rheumatism, vol. 54, no. 7, pp. 2271-2279, 2006.

[138] T. Taniguchi, Y. Asano, K. Akamata et al., "Fibrosis, vascular activation, and immune abnormalities resembling systemic sclerosis in bleomycin-treated Fli-1-haploinsufficient mice," Arthritis \& Rheumatology, vol. 67, no. 2, pp. 517-526, 2015. 

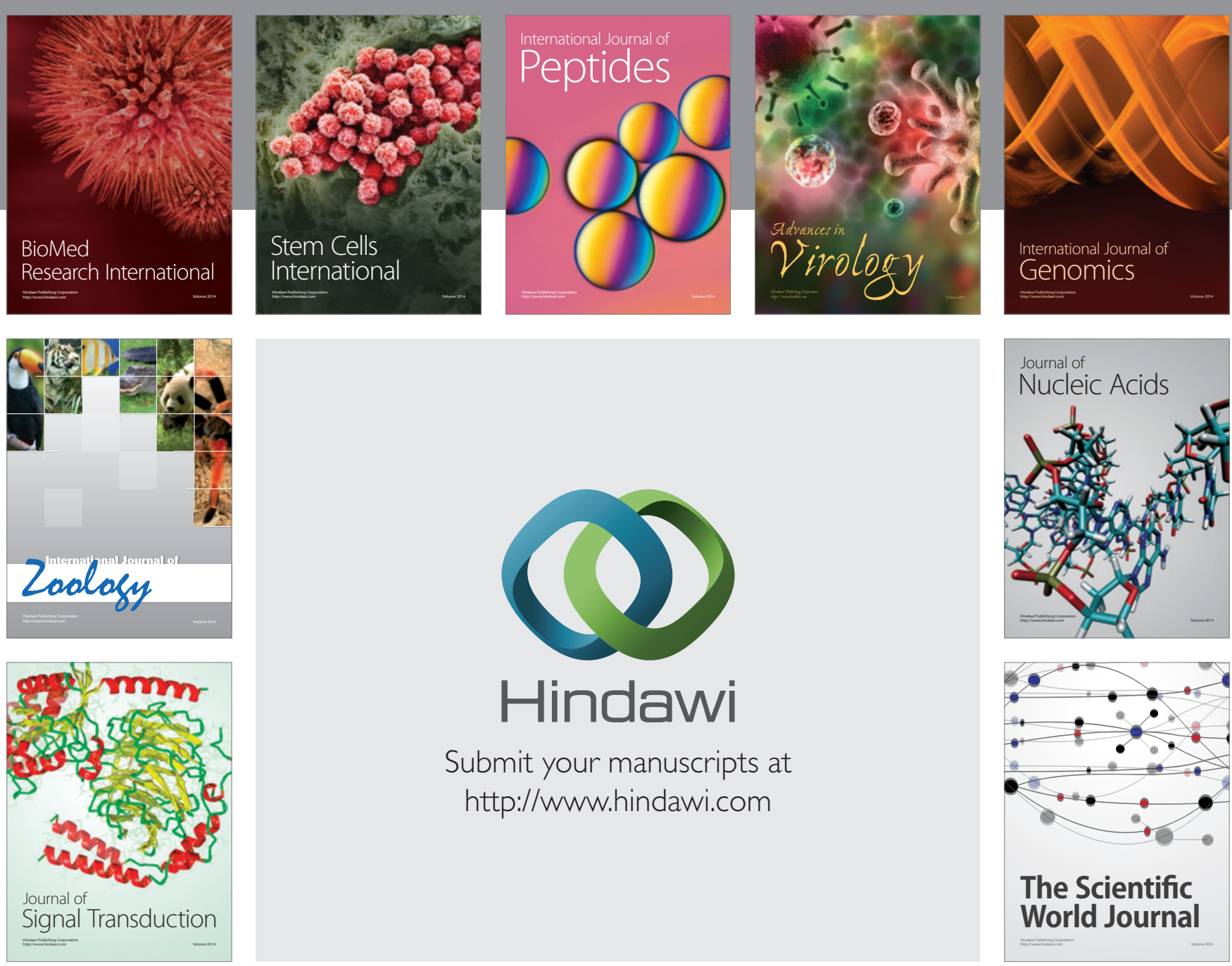

Submit your manuscripts at

http://www.hindawi.com
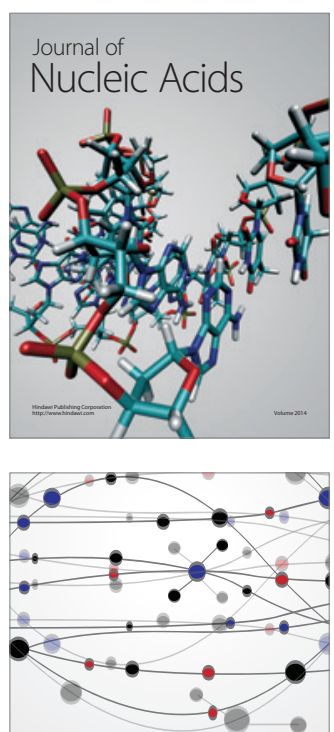

The Scientific World Journal
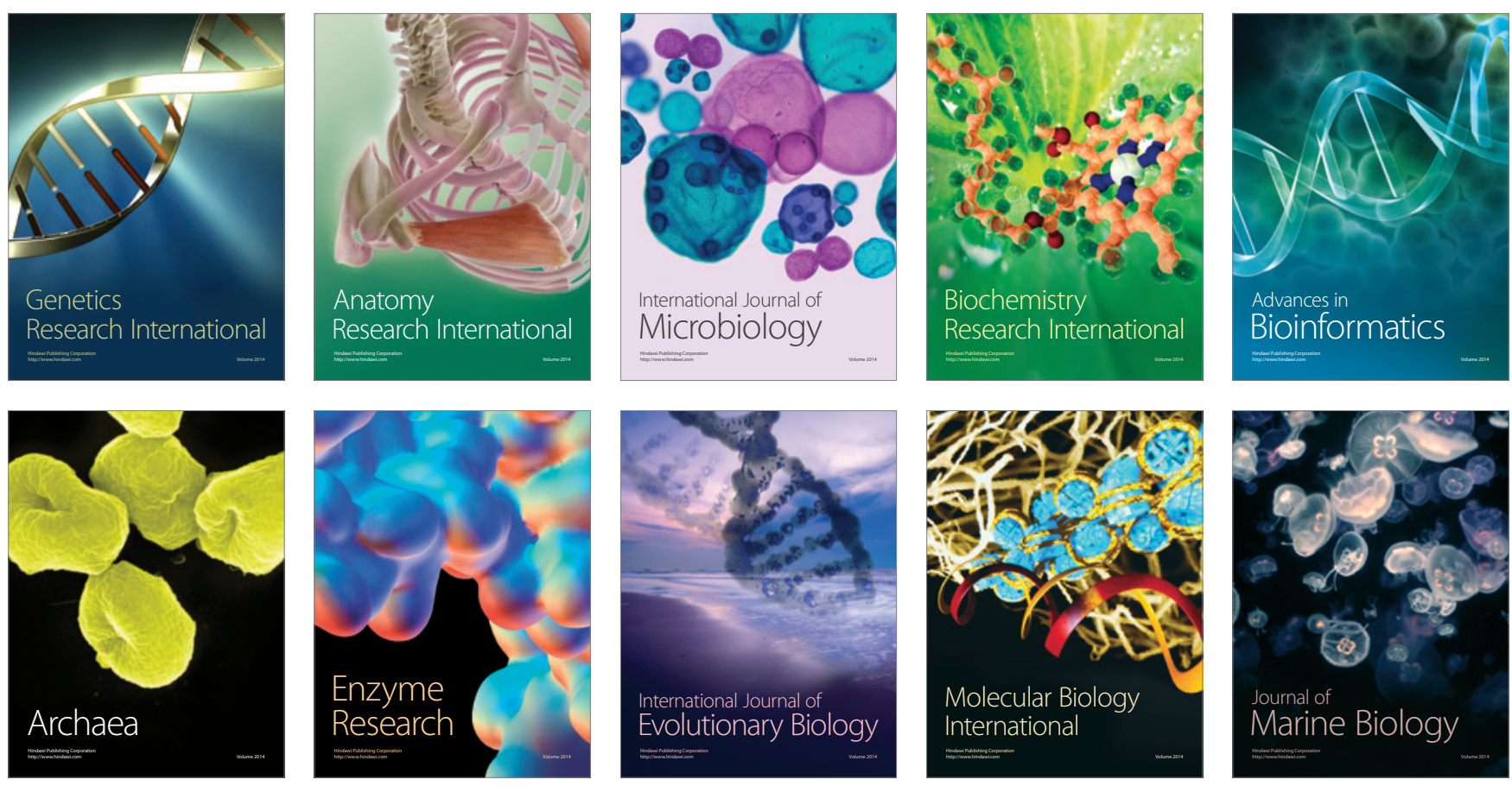